Meta

Journal des traducteurs

Translators' Journal

\title{
Précisions sur le terme " disbursement »
}

\section{André Desrochers}

Volume 13, numéro 1, mars 1968

URI : https://id.erudit.org/iderudit/002558ar

DOI : https://doi.org/10.7202/002558ar

Aller au sommaire du numéro

Éditeur(s)

Les Presses de l'Université de Montréal

ISSN

0026-0452 (imprimé)

1492-1421 (numérique)

Découvrir la revue

Citer cet article

Desrochers, A. (1968). Précisions sur le terme « disbursement ». Meta, 13(1),

27-28. https://doi.org/10.7202/002558ar d'utilisation que vous pouvez consulter en ligne.

https://apropos.erudit.org/fr/usagers/politique-dutilisation/ 


\section{PRÉCISIONS SUR LE TERME "DISBURSEMEN'T"}

Monsieur André Desrochers, directeur adjoint de l'Institut des comptables agréés de Québec, nous prie de publier les précisions qui suivent, ce que nous faisons avec d'autant plus de plaisir que l'auteur de l'article visé, $M$. Claude Schmit, délégué aux Relations publiques de l'Alcan, a également exprimé le désir de voir paraitre cette rectification.

P.A.H.

Les lecteurs de Meta sont redevables à M. Claude Schmit de les avoir éclairés dans un récent numéro ${ }^{1}$ sur la traduction du terme de comptabilité disbursement. Contrairement à Termes comptables 2 qui se satisfait du jumelage facile disbursement/déboursé, M. Schmit propose quatre équivalents (décaissement, dépense, déboursé et paiement), les compare soigneusement et recommande de généraliser l'usage de paiement (que Kettridge ne mentionne pas). Les distinctions de M. Schmit ont le mérite de faire ressortir les nuances de l'art du traducteur et de mettre le lecteur en garde contre le péril insidieux des faux amis. Je m'en réjouis.

L'article de M. Schmit contient par ailleurs deux incorrections que je me dois de relever. M. Schmit affirme que la comptabilité d'exercice ne connaît pas l'expression disbursement. Est-ce à dire que l'adoption de la comptabilité d'exercice dispense l'entrepreneur de payer ses dettes? Il eût été plus juste de dire que la comptabilité de caisse, ne dégageant pas la notion de dépense de celle de déboursé, se contente d'enregistrer les entrées et les sorties d'argent. Comme on le verra dans un instant, c'est l'objet même de la comptabilité d'exercice que de distinguer les revenus des recettes et les dépenses des déboursés.

1. Cf. Meta, vol. XII, no 3 , septembre 1967, p. 88.

2. Institut canadien des comptables agréés, éd., Termes comptables/Accounting Terms, Toronto, 1963. 
Au nombre des équivalents énumérés par M. Schmit, je relève le mot dépense. Convenons que le profane ne s'embarrasse pas toujours de distinguer entre un déboursé et une dépense. Cependant, ni le comptable ni le traducteur ne doivent commettre pareille méprise. Réduits à leur plus simple. expression, le déboursé est un mouvement de caisse (actif) de l'entreprise et la dépense, une variation de son avoir-propre (passif). Encore que le déboursé traduise le plus souvent une dépense, la comptabilité d'exercice distingue l'un de l'autre ces deux aspects d'une même opération; elle exige parfois qu'on les inscrive aux livres à des momerits différents (p. ex. frais payés d'avance, frais courus à payer), voire qu'on échelonne sur une période relativement longue l'enregistrement comptable de la dépense correspondant à un déboursé unique (amortissement des immobilisations), voire encore qu'on passe aux dépenses d'un seul coup une série de déboursés qui sont répartis sur plusieurs exercices (achat à tempérament). D'autre part, il est des déboursés qui ne se ramènent jamais à une dépense (cautionnement, achat de valeurs) et des dépenses qui ne donnent jamais lieu à un décaissement (paiement en services ou en marchandises, troc).

Jusqu'ici, les pages de META ont été quelquie peu avares des lignes consacrées à la comptabilité. Puis-je exprimer le déșir que d'autres traducteurs suivent l'exemple de M. Schmit et mettent leur compétence au service de l'art comptable.

ANDRÉ DeSROChers 